\title{
A SUPEREXPLORAÇÃO DA FORÇA DE TRABALHO RURAL NO SETOR PRODUTIVO DA SOJA EM URUÇUÍ-PI
}

\author{
Francisco Eduardo de Oliveira Cunha ${ }^{1}$ \\ Sérgio Gonçalves dos Santos Júnior²
}

\begin{abstract}
RESUMO
A expansão do agronegócio no cerrado piauiense ocorre de forma intensa e voraz, alterando a velocidade de interação do ser humano com a natureza, desrespeitando o tempo biológico desta, ajustando-a à impaciência da reprodução do capital. Com efeito, severas são as implicações sobre o trabalhador e os recursos naturais. Diante disso, o presente trabalho tem como objetivo elucidar a categoria superexploração da força de trabalho rural no setor produtivo da soja em Uruçuí-PI, com vistas a provocar reflexões acerca da realidade recente da força de trabalho rural piauiense, no intuito de compreender o seu papel na dinâmica produtiva da economia global e suas implicações no mercado de trabalho nacional e mundial. Tem-se como método de investigação e análise a Teoria Marxista da Dependência, buscando se investigar nas relações sócio produtivas estabelecidas pelo agronegócio, a categoria da superexploração da força de trabalho, desenvolvida por Ruy Mauro Marini. Como resultado, o estudo evidenciará o caráter dialético do capital agrário piauiense, onde os trabalhadores rurais produzem riquezas "alheias" e se apropriam tão somente de suas misérias, evidenciando, portanto, a tese de Marini.
\end{abstract}

Palavras-chaves: agronegócio, economia piauiense, trabalhador rural, superexploração da força de trabalho.

\section{THE SUPER EXPLORATION OF RURAL WORKFORCE IN THE SOY PRODUCTIVE SECTOR IN URUÇUÍ-PI}

\begin{abstract}
The expansion of agribusiness in the Piauí Cerrado occurs in an intense and voracious way, changing the speed of human interaction with nature, disrespecting its biological time, adjusting it to the impatience of capital reproduction. Indeed, the implications for the worker and natural resources are severe. In view of this, the present study aims to elucidate the category of super exploration of the rural workforce in the soy productive sector in Uruçuí-PI, with a view to provoking reflections about the recent reality of the rural labor force in Piauí, in order to understand their role in the productive dynamics of the global economy and its implications in the national and global labor market. The Marxist Theory of

\footnotetext{
1 Graduação em Ciências Econômicas (UFC). Especialização em Gestão Pública Municipal (UECE). Mestrado em Desenvolvimento e Meio Ambiente (UFC). Professor do Departamento de Ciências Econômicas (DECON) da Universidade Federal do Piauí (UFPI). E-mail: eduoliveira@ufpi.edu.br

2 Graduação em Ciências Econômicas (UFPI). Mestrando em Economia (UFPA). E-mail: sergiogonalves09@gmail.com
} 
Dependency is the method of investigation and analysis, seeking to investigate the socio-productive relations established by agribusiness, the category of super exploration of the workforce, developed by Ruy Mauro Marini. As a result, the study will highlight the dialectical character of Piauí's agrarian capital, where rural workers produce wealth and take ownership only of their miseries, thus evidencing Marini's thesis.

Keywords: agribusiness, Piauí economy, rural worker, super exploration of the workforce.

\section{INTRODUÇÃO}

O sociometabolismo ${ }^{3}$ do capital, na sua incessante necessidade de auto ampliação, adota em seus métodos e relações sócio produtivas, constantes encurtamentos de tempos de produção que se distanciam dos socialmente estabelecidos. Dito isto, é razoável admitir que a penetração do capitalismo na agricultura ocorra de forma intensa e voraz, numa perspectiva de alterar a velocidade de interação do ser humano com a natureza (e transformação dela), consequentemente, desrespeitando o seu tempo biológico, ajustando-a à impaciência da reprodução do capital e que concorre para as mais espúrias implicações, não somente sobre o ser trabalhador rural, mas também sobre os recursos naturais.

Diante disso, Marx (1999, p. 571) já denunciava que "todo progresso da agricultura capitalista significa progresso na arte de despojar não só o trabalhador, mas também o solo". Com isso, o referido filósofo e crítico social, evidencia que na produção capitalista, sobretudo a agrícola, somente se desenvolve sua base técnica e produtiva, exaurindo necessariamente as fontes originais de toda a riqueza produzida, a terra e o trabalhador (MARX, 1999, p. 571). Por isso, a produção capitalista deve se movimentar, e se expandir, e se ultrapassar em suas fronteiras espaciais.

Compreende-se que dentro dessa lógica de valorização e concorrência do capital no espaço agrário, é mister que os sujeitos rurais, sobretudo o pequeno produtor da agricultura familiar, migre de uma condição de produtor autônomo e independente (essencialmente criador de valores-de-uso) para o status de trabalhador rural assalariado, tornando-se, portanto, enquanto força de trabalho, uma mera mercadoria ou simples objeto de posse do capitalista. Desta forma, ter ciência deste processo de transição que perpassa desde a alienação do trabalhador rural aos seus principais meios de produção (a terra) até seu assalariamento e demais implicações sociais do capitalismo no campo, se torna essencial para a compreensão da manutenção da dependência e do subdesenvolvimento rural, especificamente na região do cerrado piauiense.

Portanto, no capitalismo, elucida-se que enquanto sociedade essencialmente produtora de mercadorias, a mercadoria força de trabalho se apresenta como elemento central e que condiciona a própria existência do modo de produção hegemônico. O trabalho humano, dessa forma, é inquestionavelmente o

\footnotetext{
${ }^{3}$ Expressão difundida pelo filósofo húngaro István Mészáros, na qual, podemos compreender o capitalismo como uma estrutura totalizante de organização, cujos elementos constitutivos - capital, trabalho e Estado se relacionam e interdependem entre si, na analogia de um organismo vivo (metabolismo social). Depreende-se, portanto, que o capitalismo assume essa capacidade de mimetismo, que o condiciona enquanto modo de produção em constante transformação e adaptação, com vistas a superar sua lógica essencialmente contraditória e autodestrutiva.
} 
elemento fundamental, imprescindível à produção de riquezas no capitalismo. Sem ele, inexiste capitalismo.

A partir desta breve discussão ora apresentada, acredita-se que a reprodução da mercadoria força de trabalho, que se confunde com a reprodução das condições materiais de existência do ser humano que oferta tal mercadoria, é tema central desta análise, principalmente quando se investigam as regiões periféricas do capitalismo, as quais se escancara a característica peculiar destas quando cotejadas as de capitalismo avançado, que é a superexploração da mercadoria força de trabalho.

Diante do exposto, o presente trabalho tem como principal objetivo elucidar a categoria superexploração da força de trabalho rural no setor produtivo da soja em Uruçuí-PI, no atual século, com vistas a provocar reflexões acerca da realidade recente da força de trabalho assalariado rural piauiense, no intuito de compreender o papel desse trabalhador na dinâmica produtiva da economia global e quais as implicações no mercado de trabalho nacional e mundial, culminando na determinação (e transferências) das taxas de mais-valia relativa, sobretudo nas áreas mais industrializadas do sistema mundo do capital.

No intuito de se investigar e compreender a relação entre o capital e a força de trabalho rural piauiense, neste trabalho se fará uso de dados secundários coletados no Ministério da Economia, na base de dados da Relação Anual de Informações Sociais (RAIS) e Cadastro Geral de Empregados e Desempregados (CAGED), submetendo-os a um tratamento analítico orientado pela Teoria Marxista da Dependência, desenvolvida por autores como Ruy Mauro Marini, Theotônio dos Santos, André Gunder Frank, Vânia Bambirra, entre outros. Para tanto, buscar-se-á contrastar os dados referentes às remunerações do trabalho, bem como da defasagem do valor histórico-moral da força de trabalho, cotejados à remuneração do capital, ao salário mínimo e ao salário mínimo necessário, este último tido como proposta metodológica para mensuração do valor da força de trabalho desenvolvida pelo Departamento Intersindical de Estatística e Estudos Socioeconômicos (DIEESE).

Enfim, acredita-se que com o presente esforço, se possa contribuir com subsídios teóricos e metodológicos para uma análise mais profícua da realidade do espaço sócio produtivo rural do Piauí, não dissociado do sistema mundo do capital, elucidando as condições a que se sujeitam os trabalhadores rurais do agronegócio da soja para a produção de riquezas no estado do Piauí, ao passo que produzem e perpetuam suas próprias misérias.

\section{TRABALHO RURAL NO CERRADO DO PIAUÍ E SUA INSERÇÃO NO CAPITALISMO GLOBAL: CONTRIBUIÇÕES TEÓRICAS DE RUY MAURO MARINI}

O estado do Piauí no ano de 2017 registrou um PIB de 45,4 bilhões, com um destacado crescimento real de 7,7\%, quando comparado aos $1,32 \%$ de crescimento do país no mesmo ano. Conforme a CEPRO (2019), fundamentada a partir de análise dos dados do IBGE (2020), o que alavancou referido desempenho no estado foi principalmente o volume de produção na Agropecuária (com 130,3\% de crescimento em relação a 2016), com destaque especial para a produção da soja, a qual apresentou acréscimo de 313,57\%, no ano de 2017, comparado a 2016.

Diante disso, é razoável afirmar que o capitalismo que se desenvolve no Piauí recente tem grande participação de seu espaço agrário, especificamente com o voluptuoso setor do agronegócio que avança na região do cerrado, sudoeste do estado, interagindo com as regiões centrais de capitalismo avançado. 
A inserção do espaço agrário piauiense na dinâmica do capitalismo global pode ser mais bem explicada por Marini (2017), quando este elucida que a integração da América Latina no desenvolvimento do capitalismo se deu a partir da necessidade da criação de uma oferta mundial de alimentos e de matérias-primas, a fim de atender a expansão industrial e da população urbana europeia e demais países centrais. Com efeito, o Piauí integra-se ao comércio mundial mediante uma imposição da divisão internacional do trabalho aos países e/ou regiões periféricas, requerendo destes uma especialização em produtos primários, enquanto aos países centrais fica a incumbência da produção de manufaturados.

A partir deste ponto, Marini (2017) desenvolve duas categorias essenciais em sua análise que são a tese das trocas desiguais e a categoria superexploração da força de trabalho, que se apresentam como centrais para a compreensão da realidade do trabalhador rural, latino-americano, brasileiro e piauiense.

Segundo Marini (2017), ao ser integrada ao mercado mundial como ofertante de alimentos e matérias-primas, a América Latina desempenha papel significativo na determinação e no aumento da mais-valia relativa nos países industriais.

Conforme elucida Marx (1999), em linhas superficiais, a mais-valia relativa refere-se às formas de exploração (consumo) da mercadoria trabalho assalariado que se dão a partir de transformações das condições técnicas de produção e que resultam na desvalorização da força de trabalho.

Ao relacionar mudanças nas condições técnicas de produção com a maisvalia relativa, Marini (2017) trata de esclarecer uma confusão costumeira entre a referida categoria marxista e o conceito de produtividade. Logo, o autor esclarece que o aumento da produtividade não necessariamente assegura aumento da maisvalia relativa, conforme explica:

Ao aumentar a produtividade, o trabalhador só cria mais produtos no mesmo tempo, mas não mais valor; é justamente esse fato o que leva o capitalista individual a procurar o aumento de produtividade, já que isso permite reduzir o valor individual de sua mercadoria, em relação ao valor que as condições gerais de produção lhe atribuem, obtendo assim uma mais-valia superior à de seus competidores - ou seja, uma mais-valia extraordinária. Dessa forma, essa mais-valia extraordinária altera a repartição geral da mais-valia entre os diversos capitalistas, ao traduzir-se em lucro extraordinário, mas não modifica o grau de exploração do trabalho na economia ou no setor considerado, ou seja, não incide na taxa de mais-valia. Se o procedimento técnico que permitiu o aumento de produtividade se generaliza para as demais empresas e, por isso, torna uniforme a taxa de produtividade, isso tampouco acarreta no aumento da taxa de mais-valia: será elevada apenas a massa de produtos, sem fazer variar seu valor, ou, o que é o mesmo, o valor social da unidade de produto será reduzido em termos proporcionais ao aumento da produtividade do trabalho. A consequência seria, então, não o incremento da mais-valia, mas na verdade a sua diminuição (MARINI, 2017, p. 329).

Diante do exposto pelo autor, fica patente que a elevação de produtividade pode concorrer para o aumento da quantidade produzida que, dadas as condições sociais (e, sobretudo técnicas) de produção, permitem redução de preço de custo individual ao capitalista que as implementa. Uma vez disseminada com os demais 
capitalistas daquele setor, a referida elevação de produtividade concorrerá para a redução do preço de custo do setor como um todo, que poderá impactar no preço de mercado do setor, no sentido de também reduzi-lo, logo, acarretar inclusive uma possível redução de mais-valia, caso não haja impactos no valor da força de trabalho.

Isso nos faz perceber que:

a determinação da taxa de mais-valia não passa pela produtividade do trabalho em si, mas pelo grau de exploração da força de trabalho, ou seja, a relação entre o tempo de trabalho excedente (em que o operário produz mais-valia) e 0 tempo de trabalho necessário (em que o operário reproduz o valor de sua força de trabalho, isto é, o equivalente a seu salário). Só a alteração dessa proporção, em um sentido favorável ao capitalista, ou seja, mediante o aumento do trabalho excedente sobre o necessário, pode modificar a taxa de mais-valia (MARINI, 2017, p. 329).

Dessa forma, o autor esclarece que a mais-valia relativa estará intimamente relacionada à redução do valor social das mercadorias que se vinculam aos bens necessários à reprodução da força de trabalho, ou seja, os bens-salário (bens de primeira necessidade, como alimentos, por exemplo). Dessa forma, somente mudanças nas condições técnicas que concorram para a redução dos preços dos bens-salário, consequentemente dos valores da força de trabalho, que estarão relacionadas à mais-valia relativa.

Com o exposto, ratifica-se o papel da América Latina na determinação do aumento de taxas de mais-valia nos países centrais, uma vez que ao prover alimentos e matérias-primas para os países industrializados, a América Latina contribui para a elevação da oferta de alimentos (bens-salários), concorrendo para a redução dos preços desses bens, consequentemente acarretando a redução do valor real da força de trabalho nos países industrializados, bem como em seu próprio contexto enquanto países periféricos.

Uma vez esclarecido esse importante papel da América Latina na determinação da mais-valia relativa, os esforços de Marini (2017) se direcionam a explicar a crença de uma dissimulada vantagem nessa relação entre o nosso continente e sua integração ao comércio mundial, a partir do que ele denomina de segredo da troca desigual.

$\mathrm{Na}$ pretensa ideia de trocas de equivalentes na sociedade capitalista (elucidado por Marx nos capítulos iniciais d'O Capital), escamoteiam-se mecanismos que permitem realizar transferências de valor, burlando as leis de troca determinadas pelos preços de produção e expressas nos preços de mercado. Com efeito, a inter-relação de regiões periféricas e centrais - com menor e maior produtividade do trabalho, respectivamente (ou entre produtores de matérias-primas e bens manufaturados) - apresenta nuances, conforme expõe Marini (2017):

E assim como, por conta de uma maior produtividade do trabalho, uma nação pode apresentar preços de produção inferiores a seus concorrentes, sem por isso baixar significativamente os preços de mercado que as condições de produção destes contribui para fixar. Isso se expressa, para a nação favorecida, em um lucro extraordinário, similar ao que constatamos ao examinar de que maneira os capitais individuais se apropriam do fruto da produtividade do trabalho. É natural que o fenômeno se apresente sobretudo em nível da 
concorrência entre nações industriais, e menos entre as que produzem bens primários, já que é entre as primeiras que as leis capitalistas da troca são exercidas de maneira plena; isso não quer dizer que não se verifiquem também entre estas últimas, principalmente quando se desenvolvem ali as relações capitalistas de produção. No segundo caso - transações entre nações que trocam distintas classes de mercadorias, como manufaturas e matérias primas - o mero fato de que umas produzam bens que as outras não produzem, ou não o fazem com a mesma facilidade, permite que as primeiras iludam a lei do valor, isto é, vendam seus produtos a preços superiores a seu valor, configurando assim uma troca desigual (MARINI, 2017, p. 331-332).

A partir da exposição do que Marini (2017) chama de troca desigual, fica patente o processo de transferência de valores (ou mais-valia), uma vez que a defasagem entre as composições de capital ${ }^{4}$ do centro e da periferia, escancara a distância da produtividade do trabalho entre ambos os espaços produtivos, condicionando aos países periféricos a perpetuarem sua condição de subdesenvolvidos e dependentes do centro, a partir da integração global.

Acerca disso, sintetiza Carcanholo (2013), quando elucida que,

Economias centrais, com tendência de possuir capitais com maior composição orgânica do capital em relação à média do seu setor e de outros setores de produção, tendem a se apropriar de um valor produzido por capitais operantes nas economias dependentes. Esta condição estrutural obriga os capitalismos dependentes, para que possam se desenvolver (CARCANHOLO, 2013, p. 83).

Marini (2017) esclarece que a lógica da manutenção desse sistema de trocas, embora desigual e desvantajosa para os países dependentes, para o capital torna-se viável, conforme apresenta o autor:

O que aparece claramente, portanto, é que as nações desfavorecidas pela troca desigual não buscam tanto corrigir o desequilíbrio entre os preços e o valor de suas mercadorias exportadas (o que implicaria um esforço redobrado para aumentar a capacidade produtiva do trabalho), mas procuram compensar a perda de renda gerada pelo comércio internacional por meio do recurso de uma maior exploração do trabalhador (MARINI, 2017, p. 332).

Dito de outra forma significa que o capital das economias dependentes, impacientes, talvez, para a realização de seus lucros, prefere reduzir salários de que elevarem suas capacidades produtivas com investimentos, consequentemente que viessem a concorrer para o aumento da composição orgânica do capital ${ }^{5}$ (elevação da produtividade do trabalho) em seus setores e/ou regiões produtivas. Até porque,

\footnotetext{
${ }^{2}$ De acordo com Marx, a composição do capital, refere-se a um relação entre o capital constante (meios de produção) e o capital variável (força de trabalho). Será melhor explanado na próxima nota de rodapé, sobre composição orgânica do capital.

5 De acordo com Marx, a composição orgânica do capital, em resumo, significa um maior volume de meios de produção (que não criam mais-valia) a serem movimentados por uma quantidade relativamente (ou absolutamente) menor de força-de-trabalho. Trata-se, portanto, de elevação das condições técnicas de produção, seja em um dado setor industrial, uma região ou um país.
} 
uma vez que produzem para fora, suas demandas independem dos salários praticados (e dos consumidores) internamente.

Diante disso, Marini (2017) apresenta o que talvez seja a categoria que melhor caracteriza a peculiaridade do capitalismo dependente, a saber, a superexploração da força de trabalho ${ }^{6}$, que se apresenta como um mecanismo de compensação em que o capitalismo dependente se utiliza para fazer frente às transferências de valor ao capitalismo central. Trata-se de uma lei de compensação, que é superexplorar (ou super consumir) a mercadoria força de trabalho, como condição de sobrevivência nessa competição desigual global, sobretudo nos seus níveis de produtividade do trabalho.

Diante do exposto, evidencia-se que, para além das transações das trocas de mercadorias, sejam matérias-primas, sejam manufaturados, a apropriação de valor realizado encobre a apropriação de mais-valia que é gerada mediante a exploração do trabalho no interior de cada nação (MARINI, 2017).

Por fim, a transferência de valor é, portanto, transferências de mais-valias. Nessa dinâmica, a América Latina e especificamente o espaço agrário no cerrado piauiense, contribuem para incrementar a taxa de mais-valia e a taxa de lucro nos países industriais centrais. Os trabalhadores latino-americanos e os trabalhadores rurais do agronegócio piauiense, por sua vez, produzem volumosas riquezas internamente em seus espaços produtivos, exportam (ou transferem) tais riquezas para fora, conforme determinado pelo centro e, permanecem tão somente com vossas misérias e a necessidade de perpetuação destas, para sobreviverem.

\section{METODOLOGIA}

Nos esforços de se investigar e compreender a geração de riqueza (e pobreza) do trabalho, observada a partir da categoria superexploração da força de trabalho no cerrado piauiense, utiliza-se neste trabalho um tratamento quanti e qualitativo, fazendo uso de variáveis econômicas especificamente do setor agropecuário (e do cultivo da soja), submetendo-as a um tratamento analítico conceitual forjado na Teoria Marxista da Dependência, desenvolvida por autores como Ruy Mauro Marini, Theotônio dos Santos, Vânia Bambirra, André Gunder Frank, entre outros.

Nesta análise, valer-se-á de dados secundários que ainda não receberam trato analítico, coletados em instituições como Instituto Brasileiro de Geografia e Estatística (IBGE), Ministério da Economia (ME), Cadastro Geral de Empregados e Desempregados (CAGED), Relação Anual de Informações Sociais (RAIS), bem como em relatórios e publicações de demais bases de institutos de pesquisas diversos, principalmente regionais.

Para elucidar a tese da superexploração da força de trabalho no setor produtivo piauiense, especificamente no agronegócio da soja predominantemente no cerrado do sudoeste do estado, buscar-se-á quantificar e contrastar dados referentes às remunerações do capital e trabalho, bem como a defasagem do valor histórico-moral da força de trabalho, cotejados aos salários mínimo e mínimo necessário, calculado pelo Departamento Intersindical de Estatística e Estudos Socioeconômicos (DIEESE). Ademais, ressalta-se que os dados analisados se balizarão no setor agropecuário e alguns deles, especificamente, nas atividades produtivas do agronegócio da soja.

\footnotetext{
${ }^{6}$ Conforme Marini, se trata do aumento da utilização da força de trabalho, e, consequentemente, da parte não remunerada que é apropriada pelo capitalista (mais-valia) sem que haja um aumento proporcional da remuneração e/ou diminuição do valor no setor de bens salário.
} 


\section{A SUPEREXPLORAÇÃO DA FORÇA DE TRABALHO RURAL PIAUIENSE}

Segundo o IBGE (2019), o bioma cerrado brasileiro é o segundo maior do país ocupando $23,3 \%$ (cerca de 2 milhões de quilômetros quadrados) do território nacional, sendo o único a estar presente em todas as regiões. De acordo com Andrade \& Viana (2015), embora os solos do cerrado fossem antes considerados impróprios para a prática agrícola, em virtude de sua aridez, teve seu uso intensificado principalmente na década de 1970, na conjuntura de expansão das fronteiras agrícolas sob os pacotes tecnológicos da revolução verde. No Piauí, conforme CEPRO (2014), o cerrado representa 11,2 milhões de hectares (cerca de $46 \%$ do solo piauiense), onde $70 \%$ se situa na região sudoeste e parte do extremo sul do estado.

Conforme Andrade \& Viana (2015), bem como Monteiro (2002), no Piauí o processo de ocupação do bioma cerrado se iniciou na década de 1970 sob a especulação fundiária como uma fase prévia à inserção na dinâmica global de produção de grãos em larga escala que ocorreu na década de 1990, intensificandose com a chegada de produtores oriundos da região Centro-Sul do Brasil. Com efeito, o cerrado do sudoeste piauiense se tornou, sobretudo no atual século, um centro de atração de produtores rurais e investidores nacionais e estrangeiros, tornando a região com papel protagonista no desempenho econômico piauiense recente.

De acordo com Santos Junior (2019), o processo de ocupação da fronteira agrícola do cerrado piauiense foi gestada não só pelos grandes capitalistas e/ou pelos latifundiários nacionais, mas também pelo capital internacional, representados por grandes corporações. Esse processo passa a ditar uma dinâmica diferente no cerrado piauiense, que deixa de ser uma produção agroextrativista, passando a ser determinada pelo aumento da produção de soja e outros grãos, bem como pelo aumento do caráter exploratório dos trabalhadores rurais. Dessa forma, a referida ocupação tem sua força propulsora nos vultosos investimentos, elevado uso de matéria-prima e uma excepcional concentração de terra, visando não mais a produção para atendimento de demanda interna, mas o mercado de commodities, projetando o cerrado piauiense para o processo de divisão internacional do trabalho.

Segundo Vilarinho et al. (2018), evidenciado nos dados do IBGE (2020), a cadeia produtiva da referida região piauiense no recente cenário, destaca-se com a produção de soja, milho, feijão, arroz, milheto, sorgo e algodão, bem como as reservas de minério de ferro, níquel, gás e petróleo; e ainda a pecuária. Entretanto, é a soja a principal commodity do agronegócio piauiense, responsável por ter colocado o Piauí como terceiro maior produtor da região Nordeste (IBGE, 2020; VILARINHO et al., 2018). A Tabela 01 apresenta os principais municípios do cerrado do estado do Piauí com participação no valor global da produção de soja. A partir dela, nota-se que o município de Uruçuí-PI tem respondido por parcela importante no valor total de produção de soja no estado, no atual século. 
Tabela 1 - Municípios do cerrado no Piauí com destaque no Valor da produção de Soja em grão (Valores em Mil Reais)

\begin{tabular}{|c|c|c|c|c|c|c|}
\hline \multirow{2}{*}{ Municípios } & \multicolumn{2}{|c|}{2002} & \multicolumn{2}{|c|}{2010} & \multicolumn{2}{|c|}{2017} \\
\hline & $\mathbf{R} \$$ & $\%$ & $\mathbf{R} \$$ & $\%$ & $\mathbf{R} \$$ & $\%$ \\
\hline Baixa Grande do Ribeiro (PI) & 9.180 & $5,41 \%$ & 137.762 & $15,68 \%$ & 782.325 & $21,17 \%$ \\
\hline Bom Jesus (PI) & 5.469 & $3,22 \%$ & 46.251 & $5,27 \%$ & 251.289 & $6,80 \%$ \\
\hline Corrente (PI) & 702 & $0,41 \%$ & 4.528 & $0,52 \%$ & 64.206 & $1,74 \%$ \\
\hline Currais (PI) & 392 & $0,23 \%$ & 25.957 & $2,96 \%$ & 151.444 & $4,10 \%$ \\
\hline Gilbués (PI) & 2.862 & $1,69 \%$ & 32.335 & $3,68 \%$ & 126.293 & $3,42 \%$ \\
\hline Monte Alegre do Piauí (PI) & 724 & $0,43 \%$ & 24.313 & $2,77 \%$ & 84.288 & $2,28 \%$ \\
\hline Ribeiro Gonçalves (PI) & 19.034 & $11,22 \%$ & 70.265 & $8,00 \%$ & 365.085 & $9,88 \%$ \\
\hline Santa Filomena (PI) & 3.438 & $2,03 \%$ & 48.928 & $5,57 \%$ & 187.938 & $5,09 \%$ \\
\hline Sebastião Leal (PI) & 3.358 & $1,98 \%$ & 36.260 & $4,13 \%$ & 114.452 & $3,10 \%$ \\
\hline Uruçuí (PI) & 18.585 & $10,95 \%$ & 162.265 & $18,47 \%$ & 706.869 & $19,13 \%$ \\
\hline Estado do Piauí & 169.698 & $100 \%$ & 878.357 & $100 \%$ & 3.695 .050 & $100 \%$ \\
\hline
\end{tabular}

Fonte: Fonte: Elaboração própria com base no IBGE (2020)

A título de análise, o referido estudo se limitará ao município de Uruçuí-PI, na Tabela 01 destacado, em virtude de seus desempenhos recentes não somente no valor da produção de soja, mas também, por responder historicamente, de 2002 a 2017 em média, por $22,29 \%$ da quantidade total de soja produzida no estado do Piauí, conforme observado no Gráfico 01.

Gráfico 1 - Participação \% na quantidade total de soja (em grão) produzida no Piauí

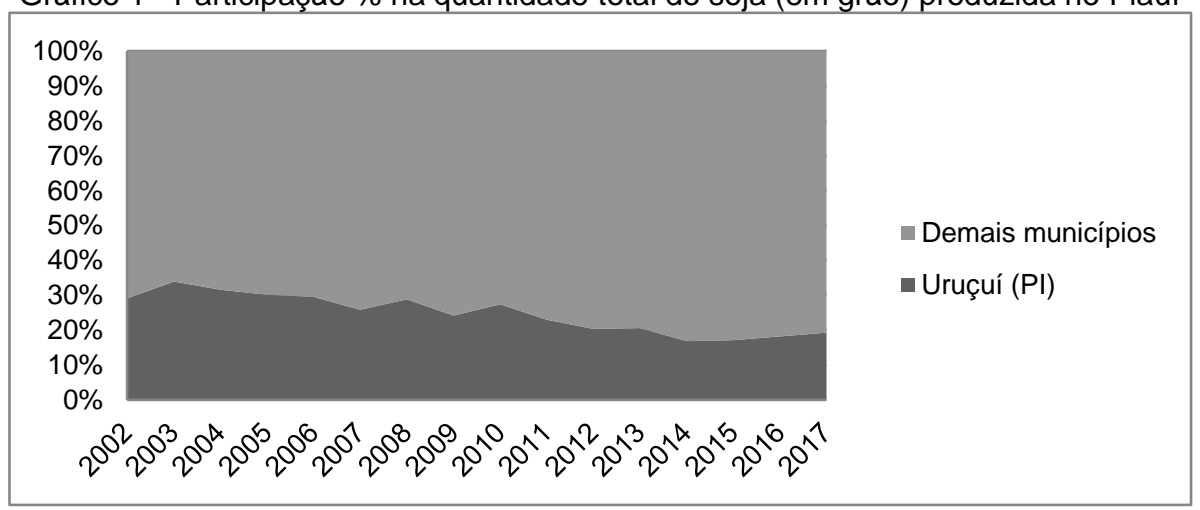

Fonte: Elaboração própria com base no IBGE (2020)

Considerando ainda a voluptuosa participação do agronegócio da soja no desempenho econômico da região do cerrado e do estado do Piauí, convém se investigar como se evidencia a categoria superexploração da força de trabalho assalariado rural no espaço agrário piauiense. 


\subsection{A SUPEREXPLORAÇÃO DA FORÇA DE TRABALHO RURAL NO SETOR PRODUTIVO DA SOJA EM URUÇUÍ-PI}

A década de 1990 foi crucial para o processo de transição econômica da região do cerrado. Segundo Santos Júnior (2019), a partir do processo de expansão do agronegócio no cerrado piauiense, a região de Uruçuí-PI e alguns municípios do seu entorno, migraram de uma economia essencialmente extrativista baseada na castanha de caju, para uma economia forjada na produção de soja. Com efeito, para que o referido fenômeno se intensificasse, era necessário um processo de transição do trabalhador rural, bem como das relações de trabalho neste setor de produção. Com isto, o trabalhador rural agora necessariamente deveria migrar para a condição de trabalhador assalariado rural (CUNHA \& SANTOS JÚNIOR, 2019).

Tal fenômeno pode ser evidenciado com a evolução da formalização dos vínculos de emprego que se expandiram descomunalmente na região e especificamente no município de Uruçuí-PI, conforme observado a partir do Gráfico 02.

Gráfico 2 - Quantidade de vínculos de emprego formais ativos no ano em Uruçuí-PI

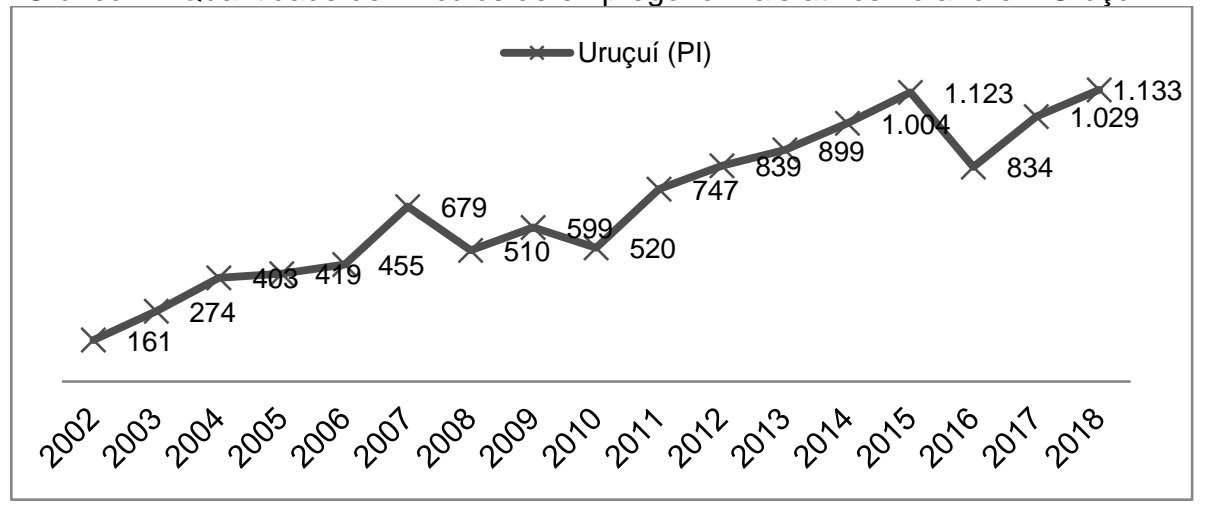

Fonte: Elaboração própria com base no ME (2020)

O Gráfico 02 atesta, portanto, a expansão dos empregos formais em Uruçuí-PI, verificando uma taxa de crescimento acumulado de 242,73\%, de 2002 a 2018. Referidos números apontam ainda para uma taxa de crescimento médio dos empregos na ordem de $16,18 \%$ ao ano.

A priori é de se deduzir que geração de emprego e renda deva corroborar para melhoria das condições de vida dos sujeitos alvos desse fenômeno, sejam capitalistas, sejam trabalhadores. Entretanto, a essência do fenômeno de apropriação desigual das riquezas geradas é dissimulada pela aparência dos números que escancaram o vigoroso desempenho econômico do agronegócio da soja piauiense, como será demonstrado no decorrer da análise. Entretanto, nesse ponto importa destacar o processo de transição do trabalhador rural informal autônomo, hegemonicamente vinculado à economia extrativista e familiar, para um trabalhador assalariado, formal e vinculado a processos produtivos patronais, em ritmos/velocidades distintos dos anteriormente verificados, bem como métodos, objetivos e condições de execução de seus trabalhos vinculados, agora, às necessidades do capital.

Ademais, quando se analisa somente o desempenho dos números (em sua aparência) e não os seres humanos ali secundarizados (a essência), perde-se de 
vista essa característica imanente à lógica de expansão capitalista - a de ser concentradora e excludente - ao passo que se insinua a disseminada retórica de melhoria da qualidade de vida e desenvolvimento socioeconômico para a região, a partir de meros números de postos de trabalho criados, sem adentrar nos aspectos específicos das relações laborais, pertinentes à precariedade das condições de trabalho, de renda, de qualificação, entre outras, provocadas pela modernização da agricultura.

Diante do exposto, é essencial se recorrer à teoria marxista da dependência, quando ela denuncia que as economias latinas (incluindo o setor rural do estado do Piauí), devido ao processo de transferência de mais-valor para as economias centrais, tem seu padrão de acumulação centrado na superexploração da força de trabalho, mecanismo este que tem como objetivo contrabalancear esse fenômeno da transferência (troca desigual). Deste modo, a referida categoria idealizada por Marini (bem como as demais categorias discutidas na teoria marxista), é uma importante ferramenta conceitual/analítica que permite compreender as relações que cercam a economia política latino-americana e, portanto, brasileira e piauiense.

Por se tratarem de variáveis não apanhadas pelos sistemas de contas regionais/nacionais oficiais, logo, não mensuráveis pela estatística econômica corrente (que mensuram preços correntes), considerando ainda que a mais-valia relativa, assim como a superexploração da força de trabalho, sejam variáveis de valor, carece-se entre os estudiosos, um modelo que balize as investigações empíricas dessas situações histórico-concretas (LUCE, 2012) em nossas economias.

Com efeito, uma das alternativas que se apresenta para se obter indícios desta superexploração é confrontando a remuneração/rendimento do capital frente ao da classe trabalhadora. Diante disso, a Tabela 02 tenta evidenciar essa comparação desigual de apropriação das riquezas em Uruçuí-PI. Nela, apresentamse o Valor Adicionado Bruto da produção do setor da agropecuária, confrontando com o valor das remunerações dos trabalhadores formais também da agropecuária.

Da diferença de ambos, obtém-se uma vaiável proxy que sugere a remuneração bruta do capital, ou seja, o lucro líquido, permitindo-se, assim, na relação remuneração do capital-trabalhador, se obter a taxa de apropriação da riqueza produzida no setor agropecuário que contribuiria inicialmente para se discutir, embrionariamente e com limitações teóricas, a categoria superexploração. 
Tabela 2 - Comparação entre Remuneração do Trabalhador x Remuneração do

Capital em Uruçuí-PI (a preços correntes) no setor Agropecuário

\begin{tabular}{|c|c|c|c|c|}
\hline Ano & Valor Adicionado Bruto & $\begin{array}{c}\text { Remuneração } \\
\text { do } \\
\text { Trabalhador }\end{array}$ & $\begin{array}{c}\text { Remuneração do } \\
\text { Capital (Lucro) }\end{array}$ & $\begin{array}{c}\text { Taxa de } \\
\text { Apropriação }\end{array}$ \\
\hline 2002 & $16.575 .000,00$ & $1.208 .391,00$ & $15.366 .609,00$ & 12,72 \\
\hline 2003 & $63.613 .000,00$ & $2.599 .030,56$ & $61.013 .969,44$ & 23,48 \\
\hline 2004 & $86.586 .000,00$ & $3.622 .335,24$ & $82.963 .664,76$ & 22,90 \\
\hline 2005 & $91.855 .000,00$ & $5.003 .108,04$ & $86.851 .891,96$ & 17,36 \\
\hline 2006 & $63.759 .000,00$ & $7.567 .287,60$ & $56.191 .712,40$ & 7,43 \\
\hline 2007 & $57.846 .000,00$ & $10.720 .799,28$ & $47.125 .200,72$ & 4,40 \\
\hline 2008 & $166.010 .000,00$ & $11.184 .590,40$ & $154.825 .409,60$ & 13,84 \\
\hline 2009 & $169.801 .000,00$ & $14.937 .401,76$ & $154.863 .598,24$ & 10,37 \\
\hline 2010 & $94.513 .000,00$ & $14.309 .642,88$ & $80.203 .357,12$ & 5,60 \\
\hline 2011 & $188.831 .000,00$ & $17.210 .918,28$ & $171.620 .081,72$ & 9,97 \\
\hline 2012 & $257.382 .000,00$ & $22.460 .207,16$ & $234.921 .792,84$ & 10,46 \\
\hline 2013 & $184.070 .000,00$ & $24.581 .405,28$ & $159.488 .594,72$ & 6,49 \\
\hline 2014 & $274.555 .000,00$ & $28.833 .694,20$ & $245.721 .305,80$ & 8,52 \\
\hline 2015 & $282.307 .000,00$ & $33.394 .587,12$ & $248.912 .412,88$ & 7,45 \\
\hline 2016 & $94.800 .000,00$ & $30.346 .861,44$ & $64.453 .138,56$ & 2,12 \\
\hline 2017 & $468.689 .000,00$ & $36.598 .613,76$ & $432.090 .386,24$ & 11,81 \\
\hline
\end{tabular}

Fonte: Elaboração própria com base no IBGE (2020) e ME (2020)

A partir da Tabela 02, observa-se no município de Uruçuí-PI um cenário crítico, uma vez que a referida tabela denuncia uma taxa de apropriação média de 10,93 entre 2002 e 2017, ou seja, a remuneração total do capital representa quase 11 vezes a remuneração do trabalho, também no período analisado.

Dessa forma, fica patente o distanciamento abissal das remunerações do capital e do trabalho de tal forma que se evidencia não somente a manutenção, mas, sobretudo o alargamento histórico, principalmente nos anos de melhores desempenhos econômicos, como é o caso dos períodos entre 2004-2005, 20082009 e no período de 2011-2015 e 2017.

O Gráfico 03, por sua sorte, oferece uma maior e melhor visibilidade a essa disparidade de apropriação entre capital-trabalho no município em análise, evidenciada na Tabela anterior descrita. 
Gráfico 3 - Contraste remuneração capital-trabalho no município de Uruçuí-PI

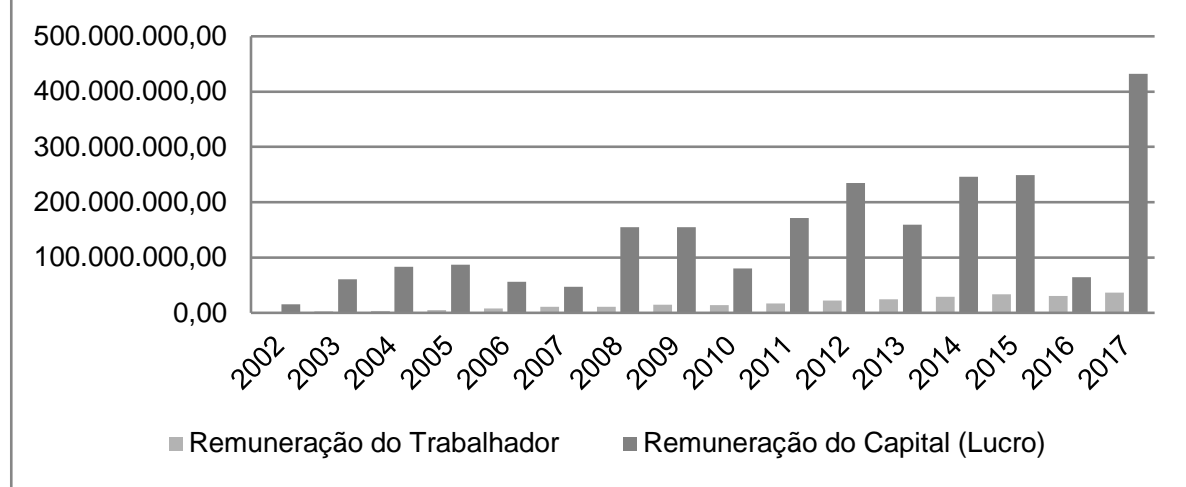

Fonte: Elaboração própria com base no IBGE (2020) e ME (2020)

De posse destas evidências, a análise marxista da forma social capitalista transcende o plano abstrato do "imaginário" e teórico, passando a ser perceptível e concreto, tomando corpo quando se contrasta a renda do trabalho e a mais-valia (lucro) apropriada pelo capitalista. Evidencia-se, portanto, que a relação que impera no capitalismo é de exploração da força de trabalho, e no caso específico do setor agropecuário piauiense, de superexploração dessa mercadoria pertencente aos trabalhadores rurais, que se intensifica e se alarga historicamente.

Diante dessa análise, têm-se condições instrumentais necessárias para a investigação da superexploração no município de Uruçuí-PI (mesmo que ainda de forma embrionária), uma vez que se pode verificar uma pequena parcela da sociedade se apropriando da maior parte da riqueza produzida, reforçando um dos pressupostos de Marx (1999) e especificamente Marini (2017), na evidência da categoria superexploração da força de trabalho.

$\mathrm{Na}$ continuidade da análise da categoria marxista da exploração e superexploração, conforme Marini (2017), com efeito, apresentar evidências ainda maiores da afirmação do caráter de superexploração no qual os trabalhadores rurais do cerrado piauiense estão submetidos, convém desenvolver uma análise da evolução histórica, contrastando o valor médio da força de trabalho ${ }^{7}$ no setor agropecuário, especificamente dos trabalhadores do cultivo da soja, com o valor do salário mínimo e do salário mínimo necessário segundo a proposição do DIEESE (2020), que podem ser verificados no Gráfico 04.

\footnotetext{
${ }^{7}$ A remuneração média do cultivo da soja foi calculada a partir dos dados obtidos junto ao CAGED/ME, obtendo-se a partir da remuneração nominal total do setor de cultivo da soja, dividida pela quantidade de vínculos formais CLT também do mesmo setor.
} 
Gráfico 4 - Comparação Remuneração Média do Cultivo da Soja* x Salário Mínimo Nacional x Salário Mínimo Necessário** no município de Uruçuí-PI

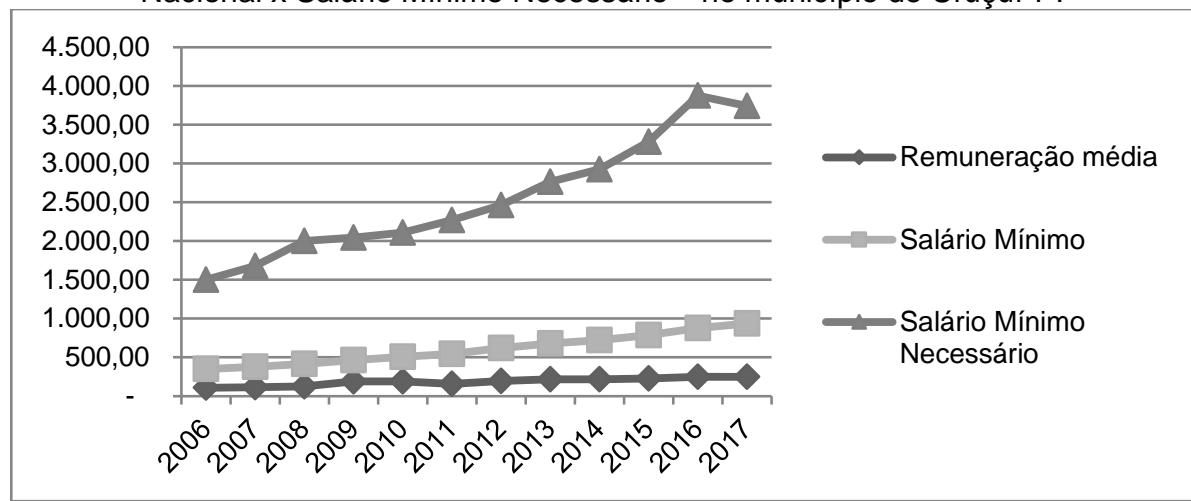

Fonte: Elaboração própria com base no ME (2020) e DIEESE (2020)

Notas: * Tabela CNAE 2.0 Subclasse Cultivo da Soja;

** Estimativa feita pelo Departamento Intersindical de Estatísticas e Estudos Socioeconômicos (Dieese), salário mínimo necessário para sustentar uma família de quatro pessoas.

Com base no Gráfico 04, enfim, evidencia-se historicamente a tese da superexploração da força de trabalho dos trabalhadores rurais da soja em Uruçuí-PI, a partir da constatação do achatamento dos salários médios nominais praticados abaixo do salário mínimo e absurdamente distante do que deveria ser o salário necessário, conforme estimativa do DIEESE (2020). Em Uruçuí-PI, no período de 2006 a 2017, o salário médio praticado no cultivo da soja representou $31,31 \%$ da média histórica do salário mínimo nacional no mesmo período.

Enfim, com esses dados cristaliza-se a ideia fundamental de Marx (1999) de que a relação da sociedade capitalista não se encontra em torno da troca de equivalentes, mas sim na relação de exploração daqueles que possuem os meios de produção sobre aqueles que não possuem outra coisa, a não ser a sua própria força de trabalho.

Na periferia, nos países dependentes, há um aviltamento dessa relação e é justamente nesse cenário que reside a importância de se resgatar a categoria superexploração de Ruy Mauro Marini, pois é ela quem "permite capturar o movimento real das relações entre capital e trabalho nas suas múltiplas dimensões, do ponto de vista da produção e circulação do valor" (LUCE, 2012, p. 126).

\section{CONSIDERAÇÕES FINAIS}

A partir das obras de Marx e Marini, fica patente que para o funcionamento do sistema mundo que se expressa a partir de uma sociedade essencialmente produtora de mercadorias, o trabalho humano se apresenta como o principal "insumo" que possibilita a expansão e a acumulação dessa lógica produtiva. Somente consumindo/extraindo o máximo possível da mercadoria-insumo força de trabalho que o capitalista consegue intensificar a acumulação e financiar sua expansão, sobretudo em países ou regiões produtivas, periféricas. O trabalho humano é, portanto, a principal mercadoria (uma pseudo commodity) que, assim como qualquer outra mercadoria, deve ser consumida ao seu esgotamento para a máxima satisfação da finalidade de quem a consome. 
A compreensão da realidade de subdesenvolvimento dependente da América Latina, do Brasil e especificamente, do espaço rural nordestino e piauiense, perpassa pela percepção de que a referida condição não é consequência de atrasos institucionais, arcaísmo do capitalismo local, estágio prévio de desenvolvimento ou até mesmo - na compreensão de alguns teóricos - falta de capitalismo. A partir da análise metodológica proposta pela teoria marxista da dependência, é razoável admitir que o subdesenvolvimento e o desenvolvimento são elementos imanentes e necessários à própria lógica de expansão e acumulação histórica do capital. São aspectos diferentes, ao passo que iguais, pertencentes ao mesmo processo dialético. Com efeito, a forma social do capitalismo traz como uma de suas principais características o desenvolvimento desigual.

Portanto, ao entender essa forma social hegemônica - que se denomina capitalismo - como um sistema-mundo, interligado local e globalmente, percebe-se que o urbano e o rural, o centro e a periferia, são indissociáveis. Com efeito, o meio rural tem papel fundamental no processo socioeconômico e nas transformações germinais ocorridas durante o processo de (re)organização do capital, uma vez que foi nele onde primeiro se verificou os impactos da política de cerceamento e da violência do estado, bem como deu subsidio a formação do exército industrial de reserva nos burgos e incipiente indústria europeia do século XVIII.

$\mathrm{Na}$ periferia, onde a divisão internacional do trabalho especializou o continente latino-americano (especificamente o Brasil agrário e o cerrado piauiense) como uma colônia agroexportadora, o principal espaço sócio produtivo atingido numa remontada do sistema capitalista em sua manifestação mais intensa aqui no país, foi o espaço rural.

Dessa maneira, dentro da (re)integração do capitalismo brasileiro à dinâmica global de produção, o cerrado piauiense passou a ser ocupado e teve seu modo de produção completamente alterado. A referida região produtiva passou a produzir commodities e a ser integrada ao mercado internacional. Desta maneira a produção, que antes era pautada no modo agroextrativista, com trabalhadores rurais independentes, tornou-se agora, hegemonicamente, uma produção nos moldes capitalistas, onde os trabalhadores passam a depender quase que exclusivamente do mercado para sua sobrevivência, ao passo, ter sua expropriação de forma permanente. Entretanto, convém destacar que nesse processo também se observam tensões que ratificam a dialética do capitalismo atuante no espaço agrário, uma vez que se manifestam movimentos de contra tendência, imanentes à relação conflituosa entre capital-trabalho.

É na busca de compreender tais transformações sócio produtivas ocorridas após a subsunção do cerrado piauiense ao capital, que nos deparamos como a similaridade e conseguimos sustentar a tese de Ruy Mauro Marini, a qual afirma que as economias dependentes são fundamentalmente pautadas na superexploração da força de trabalho. Municiados dos dados ora apresentados nesse estudo, aqui podemos, mesmo que embrionariamente, atestar a veracidade da categoria superexploração da força de trabalho no espaço rural do Piauí, especificamente no agronegócio da soja, praticado no município de Uruçuí-PI.

A partir da análise teórica e instrumental, se acredita que o presente estudo cumpre com o seu objetivo ao denunciar que o trabalhador latino-americano e, consequentemente o trabalhador piauiense da região do agronegócio do cerrado, tem sua relação produtiva com o capital forjada na superexploração da força de trabalho, tendo seu desgaste prematuro, uma vez que as evidencias mostraram uma maior intensificação do consumo da mercadoria da força de trabalho sem o devido acompanhamento do pagamento de bens-salário na mesma proporção, sobretudo 
em períodos de desempenho econômico-numérico considerável no setor agropecuário.

Ao se analisar a relação do valor da força de trabalho com o salário mínimo e ainda, com a proposição de salário mínimo necessário apresentado pelo Departamento Intersindical e Estudos Socioeconômicos (DIEESE), vê-se que o valor (e preço) atribuído ao trabalho, pago pelo capitalista, passa longe de atender as necessidades mais básicas do trabalhador, enquanto equivalente necessário à reprodução de suas condições materiais de existência e no caso especificamente do trabalhador rural piauiense, a subsistência sua e dos seus.

Por fim, entende-se que a referida investigação teórica retrata a essência da realidade dos trabalhadores assalariados rurais do agronegócio piauiense, ao qual se lançam diariamente na vil esperança de melhoria de suas condições de vida por serem "beneficiados" com os trabalhos formalizados pelo capitalismo rural, mas que têm como única certeza o fato de criarem volumes consideráveis de riquezas para o agronegócio mundial, se apropriando tão somente de suas próprias misérias e em proporções desumanas.

\section{REFERÊNCIAS}

ANDRADE, P. S.; VIANA, M. R. A questão fundiária sob o impacto do agronegócio no Cerrado Piauiense. Rev. FSA, Teresina, v. 12, n. 4, art. 13, p. 207-229, jul./ago. 2015.

BAMBIRRA, V. O capitalismo dependente latino-americano. 3. ed. Florianópolis: Insular, 2015.

CARCANHOLO, M. D. (Im)precisões sobre a categoria superexploração da força de trabalho. In: Desenvolvimento e Dependência: cátedra Ruy Mauro Marini / FILHO; N. A. (Org.). Brasília: Ipea, 2013.

CEPRO. FUNDAÇÃO CENTRO DE PESQUISAS ECONÔMICAS E SOCIAIS DO PIAUÍ. Cerrados piauienses: estudo e análise de suas potencialidades, impactos da exploração da riqueza sobre a população da região. Teresina: CEPRO, 2014.

CEPRO. SUPERINTENDÊNCIA DE ESTUDOS ECONÔMICOS E SOCIAIS. PIB do estado do Piauí 2017. Teresina: CEPRO, 2019.

CUNHA, F. E. O.; SANTOS JUNIOR, S. G. Intensificação e superexploração da força de trabalho dos assalariados rurais no cerrado piauiense. In: XIV CONGRESSO DA SOCIEDADE BRASILEIRA DE ECONOMIA, ADMINISTRAÇÃO E SOCIOLOGIA RURAL (SOBER NE). XIV., Bacabal, Anais... Bacabal, 2019.

DIEESE. Departamento Intersindical de Estatística e Estudos Socioeconômicos. Salário mínimo nominal e necessário. Disponível em: https://www.dieese.org.br/ analisecestabasica/salarioMinimo.html. Acesso em: 09 abr. 2020.

FRANK, G. A. América Latina: subdesarrollo o revolución. Ciudad de México: Ediciones Era, 1973.

FRANK, G. A. El desarollo del subdesarollo. Pensamiento Crítico, Habana, n. 7, ago. 1967. 
IBGE. INSTITUTO BRASILEIRO DE GEOGRAFIA E ESTATÍSTICA. Biomas e Sistemas Costeiro-Marinhos do Brasil. IBGE. Rio de Janeiro: IBGE, 2019. Disponível em: https://www.ibge.gov.br/apps/biomas. Acesso em: 20 mar. 2020

IBGE. INSTITUTO BRASILEIRO DE GEOGRAFIA E ESTATÍSTICA. Pesquisa Agropecuária Municipal. Disponível em: https://sidra.ibge.gov.br. Acesso em: 07 abr 2020 .

LUCE, M. S. A superexploração da força de trabalho no Brasil. Revista Soc. Bras. Economia Política, São Paulo, n. 3, p. 119-141, jun. 2012.

MARINI, R. M. Dialética da dependência. Germinal: Marxismo e Educação em Debate, Salvador, v. 9, n. 3, p. 325-356, dez. 2017.

MARX, K. O Capital: crítica da economia política. Livro 1. 17. ed. Rio de Janeiro: Civilização Brasileira, 1999.

ME. MINISTÉRIO DA ECONOMIA. RAIS. Relatório Anual de Informação Social Disponível em: http://bi.mte.gov.br/bgcaged/login.php. Acesso em: 07 abr. 2020.

MONTEIRO, M. S. L. Ocupação do Cerrado piauiense: estratégia empresarial e especulação fundiária. 227 p. Tese (Doutorado) - Instituto de Economia, Universidade Estadual de Campinas, 2002.

SANTOS, T. dos. Socialismo o fascismo: el nuevo carácter de la dependencia y el dilema latinoamericano. México, editora Edicol, 1978.

SANTOS, T. dos. Imperialismo e dependência. México: Era, 1986.

SANTOS JUNIOR, S. G. Intensificação e superexploração do trabalho assalariado rural no cerrado piauiense entre 1990 e 2017. Monografia Departamento de Ciências Econômicas, Universidade Federal do Piauí, 2019.

VILARINHO, L. S.; LOPES, W. G. R.; MONTEIRO, M. S. L. Desenvolvimento e capital social no agronegócio do Cerrado do Piauí, Brasil. R. Tecnol. Soc. v.14, n. 30 , p. 30-46, jan./abr. 2018. 